\title{
Secretion of polyhydroxybutyrate in Escherichia coli using a synthetic biological engineering approach
}

\author{
Asif Rahman, Elisabeth Linton, Alex D Hatch, Ronald C Sims and Charles D Miller
}

\begin{abstract}
Background: Polyhydroxyalkanoates (PHAs) are a group of biodegradable plastics that are produced by a wide variety of microorganisms, mainly as a storage intermediate for energy and carbon. Polyhydroxybutyrate (PHB) is a short-chain-length PHA with interesting chemical and physical properties. Large scale production of PHB is not wide-spread mainly due to the downstream processing of bacterial cultures to extract the PHB. Secretion of PHB from Escherichia coli could reduce downstream processing costs. PHB are non-proteinaceous polymers, hence cannot be directly targeted for secretion. Phasin, PhaP1, is a low molecular weight protein that binds to PHB, reducing PHB granule size. In this study PHB is indirectly secreted with PhaP1 from E. coli via type I secretion using HlyA signal peptides.

Results: This study demonstrated the successful secretion of phasin and phasin bound PHB outside of the cell and into the culture medium. The secretion of PHB was initiated between 24 and $48 \mathrm{~h}$ after induction. After $48 \mathrm{~h}$ of culturing, $36 \%$ of the total PHB produced in the secreting strain was collected in the secreted fraction and $64 \%$ remained in the internal fraction. To further support the findings of this study, the PHB secretion phenomenon was observed using SEM.
\end{abstract}

Conclusions: From this study, the ability to use type I secretion to: 1) secrete phasin and 2) successfully secrete PHB has been shown.

Keywords: Polyhydroxyalkanoates, PHA, PHB, Secretion, Phasin, Translocation, HlyA, Synthetic biology

\section{Background}

Fossil derived plastics are non-biodegradable and toxic to the environment. Based on an United States Environmental Protection Agency study in 2011, there was an increase in non-biodegradable plastic accumulation in municipal solid waste systems from $0.5 \%$ to $12.4 \%$ during 1960 to 2010 [1]. Alternative means of producing plastics in large quantities that are both economically and environmentally friendly have recently gained considerable attention [2].

Replacing traditional plastic with biodegradable plastic such as polyhydroxyalkanoates (PHAs) can potentially reduce total waste by up to $20 \%$ [3]. PHAs are produced by a variety of microorganisms as an intercellular storage

\footnotetext{
* Correspondence: charles.miller@usu.edu

Department of Biological Engineering, Utah State University, 4105 Old Main Hill, Logan 84322-4105, UT, USA
}

(c) 2013 Rahman et al.; licensee BioMed Central Ltd. This is an open access article distributed under the terms of the Creative Commons Attribution License (http://creativecommons.org/licenses/by/2.0), which permits unrestricted use, distribution, and reproduction in any medium, provided the original work is properly cited.

medium for energy and carbon and can accumulate up to $90 \%$ of the cell dry weight [4]. PHAs are biodegradable polymers. The biodegradability can range from days [5] to months [6] with degradation either taking place extracellularly or intracellularly. Extensive review on degradation of PHAs can be found in $[7,8]$. There are 155 different confirmed types of PHA monomer subunits, each with varying monomer repeat number and side groups [9]. Additionally, PHAs have melting temperatures between $50-180^{\circ} \mathrm{C}$ and crystallinity of $30-70 \%$ [10]. Thus, PHAs have a variety of possible applications, that could replace traditional plastics derived from petroleum [11]. Some of the possible applications are highlighted in previous studies $[12,13]$ and include: packaging, medical uses [14], agricultural uses, and in carbon nanotubes [15].

Polyhydroxybutyrates (PHB) are a short-chain-length (scl) PHA polyester with between 3-5 carbon monomers [9]. The production of PHB in recombinant systems such 
as Escherichia coli has been made possible by the isolation of the phaCAB operon from Ralstonia eutropha (Cupriavidus necator) and cloning into pBluescriptSK- to generate plasmid pBHR68. pBHR68 has been widely used for recombinant production of $\mathrm{PHB}$ in E. coli. The phaCAB operon is a three-step enzymatic process by which acetyl-CoA is converted to PHB: phaC (PHA synthase), phaA ( $\beta$-ketothiolase), and phaB (acetoacetyl-CoA reductase) $[4,16]$. After production of $\mathrm{PHB}$, the $\mathrm{PHB}$ polymer forms spherical granules with a hydrophobic core and attached proteins at the surface, including PHA synthase and phasin, PhaP1 [17-19].

The cost of producing PHAs is approximately US\$ 4-6/ $\mathrm{kg}$ and one of the major bottlenecks in scaling up recombinant $\mathrm{PHA}$ production systems is the isolation of the PHAs $[12,20]$. Current techniques that are used to isolate PHB from E. coli are invasive, including mechanical, chemical, and biological treatments. These techniques involve lysing the cellular membrane prior to isolation of the PHBs. There are a variety of methods that have been suggested for recovery of PHBs from microorganisms and a detailed review of the different $\mathrm{PHB}$ isolation methods is outlined in [20].

The development of a secretion mechanism eliminates the need for cell disruption by mechanical or chemical means, and may lead to continuous (or semi-continuous) PHB production systems. In gram-negative bacteria like $E$. coli, compounds are exported via six major secretory pathways [21-24]. Recombinant proteins can be targeted to type I and II secretory pathways through genetic fusion with signal peptide targeting sequences.

PHBs are non-proteinaceous polyesters and therefore cannot be directly targeted for translocation by signal peptide fusion. Phasins are low-molecular weight proteins that play a role in PHB granule formation by binding to the PHB granule surface $[19,25]$. Phasins are structural proteins found in organisms that naturally produce PHAs and are similar in function to oleosins which are found in plants $[19,26]$. Currently, oleosins are used to purify various compounds such as pharmaceuticals from plants [27].

Translocation of PHBs is possible through optimization of granule size, which reportedly varies from 50 to $1,000 \mathrm{kDa}$ based on growth parameters and host strain [4]. One of the functions of phasin is to increase the surface-to-volume ratio of granules so that higher accumulation levels can be achieved [25,28,29]. Therefore, the size of the PHB granule can be decreased significantly through phasin overexpression. In one such study, overexpression of phasin resulted in a decrease of $\mathrm{PHB}$ granules from 70-310 nm diameter to 20-60 nm [28].

Type I secretion is a simple one step secretion system that can translocate proteins from the cytoplasm to the extracellular medium without protein interaction with the periplasm [30]. Proteins of nearly $900 \mathrm{kDa}$ (large adhesion protein, $L a p A$ ) have reportedly been secreted to the extracellular milieu by the type I secretory mechanism of gram-negative bacteria [31,32]. Specifically using the Hemolysin (HlyA) secretion mechanism proteins such as $\beta$-galactosidase $(117 \mathrm{kDa})$ [33], $\beta$-gal-OmpF (56 kDa) [34], and green fluorescent protein (GFP) (27 kDa) [35] have been secreted by $E$. coli. The physical characteristics of the secretion channel are approximately $3.5 \mathrm{~nm}$ in diameter with a length of $14 \mathrm{~nm}$ as reported by Fernández et al., which makes the secretion phenomena of large proteins very interesting [36].

Our group has previously used a synthetic biological engineering approach to demonstrate the feasibility of HlyA, GeneIII, PelB, and TorA secretion systems in $E$. coli with the use of GFP [35]. From the aforementioned study, the type I secretion system using the HlyA signal peptide yielded the best results for secretion of GFP outside of the cell and into the medium [35]. The objective of this study was to demonstrate that phasin can be used to secrete $\mathrm{PHB}$ from E. coli using type I secretion machinery.

\section{Results and discussion}

Initial studies were carried out to demonstrate expression and then successful translocation of phasin, PhaP1, into the extracellular medium. Once this was demonstrated, PHB secretion experiments were conducted that included: growth studies, PHB production in secreted and non-secreted fractions, and visualization with scanning electron microscopy (SEM).

\section{Analysis of phasin translocation}

For E. coli cells expressing pCMEL1 and pLG575, a phasin band is observed at $22-26 \mathrm{kDa}$ in the cytoplasmic fraction, the periplasmic fraction, the membrane fraction, and the concentrated extracellular media (Figure 1). This polyacrylamide gel and corresponding immunoblot demonstrated: 1$)$ the ability for $E$. coli to produce non-codon optimized Phasin (from R. eutropha), a protein not naturally expressed in E. coli and 2) translocation of phasin into different fractions of the cell. Compared to other studies that focused non-translocated phasin, the phasin band sizes in all of the different fractions are similar $[19,29]$. Since the translocation of phasin was successful, secretion of PHB using phasin was then attempted.

\section{Growth studies}

The PHB secreting strain consisted of pCMEL3 + pLG575, whereas the non-secreting strain consisted of pBHR68+ pLG575. From the CFU/mL vs. time graph (Figure 2) stationary phase was reached at approximately $8-12 \mathrm{~h}$ for both non-secreting and secreting strains. The nonsecreting and secreting strains had the highest overall 


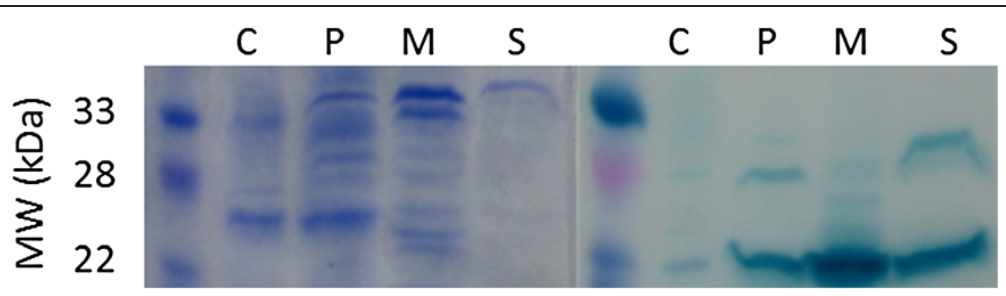

Figure 1 SDS polyacrylamide gel and corresponding immunoblot of subcellular fractions for PhaP1:HlyA. C - cytoplasmic fraction, $\mathrm{P}$ - periplasmic fraction, $\mathrm{M}$ - membrane fraction, $\mathrm{S}$ - concentrated supernatant (media) fraction. The position of phasin bands varies from roughly $22-26 \mathrm{kDa}$.

$\mathrm{CFU} / \mathrm{mL}$ at approximately $9 \times 10^{12}$ and $5 \times 10^{12} \mathrm{CFU} / \mathrm{mL}$, respectively, after $12 \mathrm{~h}$. There was no significant difference between $\mathrm{CFU} / \mathrm{mL}$ for the non-secreting and secreting strains after 24 and $48 \mathrm{~h}(\mathrm{p}>0.05)$. This statistical analysis on the $\mathrm{CFU} / \mathrm{mL}$ demonstrated that there were no significant differences in $E$. coli growth between the two samples at times when PHB analysis was conducted ( 24 and $48 \mathrm{~h}$ ). Furthermore, this suggests that the secretion of PHB does not affect cell viability.

\section{PHB production analysis}

PHB production analysis was carried out 24 and 48 because after $24 \mathrm{~h}$ the $E$. coli harboring the plasmid systems were in stationary phase. Previous studies demonstrated that PHB did not accumulate to significant levels during the exponential growth phase. Acetyl-CoA is required for cell synthesis during the exponential phase but is diverted to produce PHB in the stationary phase, thus, there is a delay between carbon source utilization and PHB production [37].

PHB measured inside the cell is defined as the internal fraction and $\mathrm{PHB}$ collected by the $\mathrm{CaCl}_{2}$ precipitation method is the secreted fraction. $24 \mathrm{~h}$ after induction, the internal fraction of the cells demonstrated PHB production for both the secreting and non-secreting strains. While the non-secreting strain accumulated approximately $41.93 \pm$ $13.5 \%$ of PHB in the dry cell weight at $24 \mathrm{~h}$, the secreting strain accumulated approximately $28.85 \pm 0.41 \%$ (Table 1 ). $48 \mathrm{~h}$ after induction the non-secreting and secreting strains had accumulated $47.24 \pm 6.0 \%$ and $38.80 \pm 15.5 \%$ PHB, respectively. There was no significant statistical difference seen in internally accumulated PHB in either the nonsecreting or secreting strains at 24 and $48 \mathrm{~h}(\mathrm{p}>0.05)$ after induction. The internal levels of PHB accumulation in the non-secreting and secreting strains are comparable to those seen in other studies such as [38], where the authors showed accumulation of $42 \%$ PHB in E. coli DH5 $\alpha$ harboring pBHR68 after 24-48 h [38].

PHB secreted fractions were analyzed at 24 and $48 \mathrm{~h}$ after induction for the secreting and non-secreting strains. PHB harvested in the secreted fraction of the non-secreting strains was $0.31 \pm 0.35 \%$ and $0.72 \pm 0.89 \%$, respectively. The PHB present in the secreted phase demonstrated that some lysed cells containing PHB were found in this fraction after $\mathrm{CaCl}_{2}$ precipitation. This is to be expected from a differential centrifugation technique, such as that used in this study. 24 and $48 \mathrm{~h}$ after induction, the

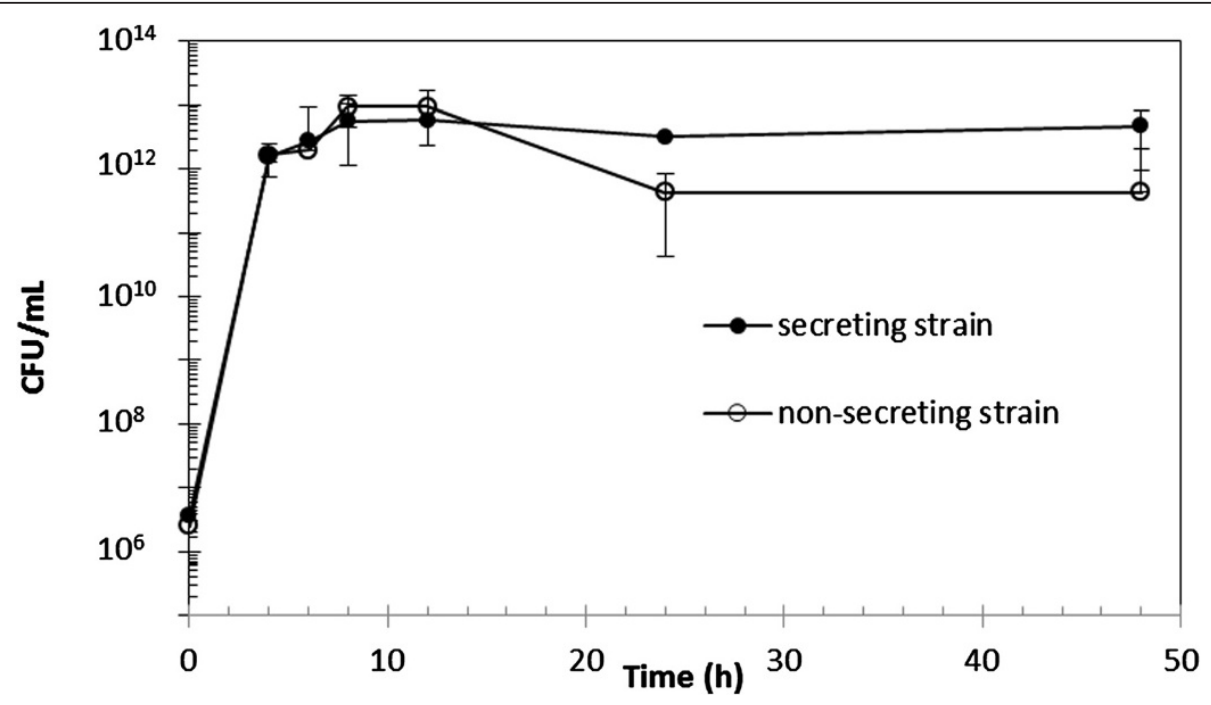

Figure $2 \mathrm{CFU} / \mathrm{mL}$ vs. Time (hours) for secreting and non-secreting strains of PHB producing E. coli, averaged from triplicate experiments (one standard deviation shown). 
Table 1 Production of PHB in secreting (pCMEL3 + pLG575) and non-secreting (pBHR68 + pLG575) strains of E. coli at 24 and $48 \mathrm{~h}$

\begin{tabular}{|c|c|c|c|c|c|c|c|}
\hline \multirow[b]{2}{*}{ Strain } & \multirow[b]{2}{*}{ Time (h) } & \multicolumn{2}{|c|}{$\%$ mass of PHB in dry mass } & \multicolumn{3}{|c|}{ Production $\mathrm{g} / \mathrm{L}$ PHB } & \multirow[b]{2}{*}{$\begin{array}{l}\text { g PHB/g } \\
\text { Glucose }\end{array}$} \\
\hline & & $\begin{array}{l}\text { Secreted } \\
\text { fraction }\end{array}$ & $\begin{array}{l}\text { Non- secreted } \\
\text { fraction }\end{array}$ & $\begin{array}{l}\text { Secreted } \\
\text { fraction }\end{array}$ & $\begin{array}{l}\text { Non-secreted } \\
\text { fraction }\end{array}$ & $\begin{array}{l}\text { Total } \\
\text { production }\end{array}$ & \\
\hline \multirow[t]{2}{*}{ Non-secreting } & 24 & $0.31 \pm 0.35$ & $41.93 \pm 13.5$ & $0.40 \pm 0.27$ & $5.65 \pm 1.1$ & $6.05 \pm 1.1$ & $0.40 \pm 0.07$ \\
\hline & 48 & $0.72 \pm 0.89$ & $47.24 \pm 6.0$ & $0.50 \pm 0.41$ & $5.43 \pm 1.7$ & $5.93 \pm 1.8$ & $0.40 \pm 0.12$ \\
\hline \multirow[t]{2}{*}{ Secreting } & 24 & $0.69 \pm 0.18$ & $28.85 \pm 0.41$ & $0.40 \pm 0.06$ & $3.42 \pm 0.33$ & $3.82 \pm 0.3$ & $0.25 \pm 0.02$ \\
\hline & 48 & $28.29 \pm 7.2^{*}$ & $38.80 \pm 15.5$ & $2.57 \pm 0.75^{*}$ & $4.58 \pm 2.47$ & $7.15 \pm 2.6$ & $0.48 \pm 0.17$ \\
\hline
\end{tabular}

*Indicates statistical significance within column $(p<0.05)$.

secreting strain produced $0.69 \pm 0.18 \%$ and $28.29 \pm 7.2 \%$ respectively in the secreted fraction. The level of PHB seen in the secreted fraction of the secreting strain was statistically significant after $48 \mathrm{~h}$ post induction, compared to the non-secreting strain $(\mathrm{p}<0.05)$. This increase in PHB present in the secreted phase after $48 \mathrm{~h}$ indicates that the secretion system is functioning and producing higher amounts of $\mathrm{PHB}$, with a small amount of non-secreted PHB ending up in the secreted fraction. These results demonstrate that PHB secretion is initiated $24 \mathrm{~h}$ after induction.

Secretion of PHB can help in downstream processes by aiding in PHB separation from biomass. Of the total PHB produced by the secreting strain after $48 \mathrm{~h}, 36 \%$ was collected in the secreted fraction and the remaining $64 \%$ was in the internal fraction. The secreting strain had a total PHB production of $7.15 \mathrm{~g} / \mathrm{L}$ compared to $5.93 \mathrm{~g} / \mathrm{L}$ for the non-secreting strain after $48 \mathrm{~h}$ post induction.

It has been demonstrated from previous studies that PHB can accumulate in larger quantities in E. coli when using a bioreactor compared to a shaker flask. A fedbatch bioreactor study by Choi et al. 1999, reported accumulation of up to 77\% PHB of dry cell weight [39] and another study reported accumulation of up to $80 \%$ [37]. Future studies will be performed to determine how well the secreting strain performs under similar bioreactor growth conditions.

\section{SEM analysis}

SEM is not widely used for PHB analysis since a surface topographical analysis is typically of little use. SEM has however been used to visualize PHA granules produced from recombinant E. coli [40] and PHA degradation from a variety of organisms [41]. In the case of secretion, SEM can provide images of what is occurring at the surface of $E$. coli during the secretion process. Figure 3A shows a PHB non-secreting $E$. coli strain harboring the pBHR68 plasmid. Figure 3B shows E. coli that is accumulating $\mathrm{PHB}$ and overexpressing phasin. Figure $3 \mathrm{C}$ shows the full secretion system in E. coli (pCMEL3+ pLG757). Figure $3 \mathrm{C}$ suggests that PHB is being secreted outside of the bacteria and into the medium. These observations further demonstrate the functioning of the PHB secretion system.

The SEM photo in Figure $3 \mathrm{C}$ suggests that secretion of PHB occurs at the polar regions of the cell. Interestingly it has been found in previous studies $[42,43]$ that PHB granule formation occurs at the cell poles in E. coli when both phasin and PHB are being produced. When PHB is being produced the interpretation is that PHA synthase is active, and it has previously been suggested that PHA synthase has polar targeting information [43].

It is interesting that E. coli is able to secrete PHB through pore sizes of $3.5 \mathrm{~nm}$ [36] in diameter. From the results of this this study not all the PHB produced is
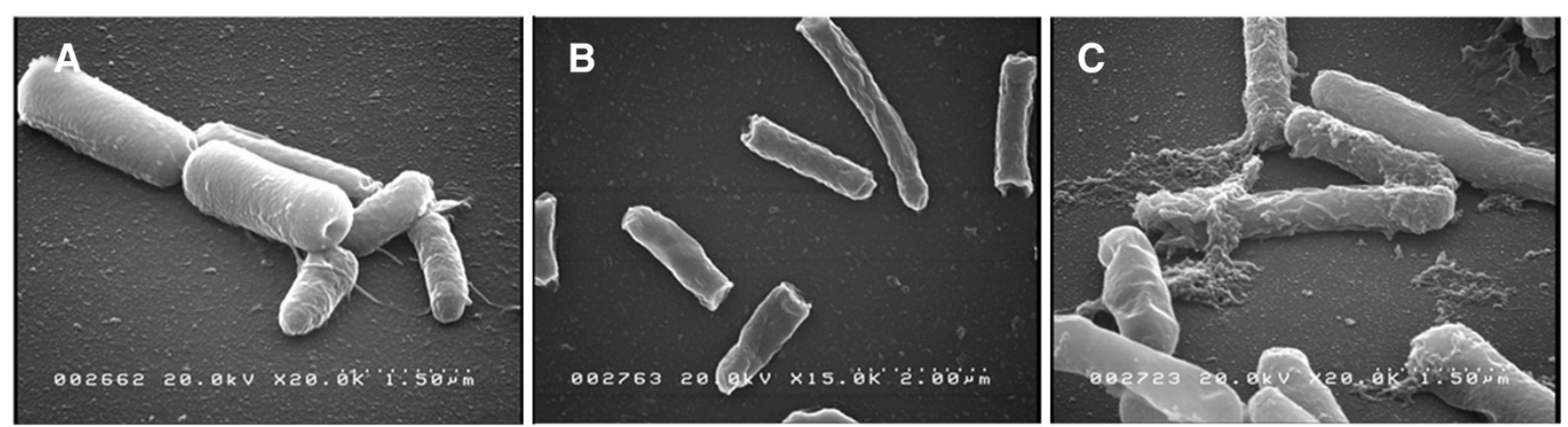

Figure 3 SEM images taken from overnight cultures of $E$. coli XL1Blue harboring different plasmid systems: A) pBHR68 (non-secreting), B) PCMEL3 (non-secreting with phasin overexpression), and C) PCMEL3 + pLG575 (complete PHB production and secretion system). 
being secreted, suggesting there could be differences between the secreted and non-secreted PHB.

\section{Conclusions}

This study demonstrated the successful expression of phasin, PhaP1, and its translocation using type I secretion in E. coli. Once translocation of PhaP1 was successful, a recombinant synthetic biological system to secrete PHBs was designed and tested. Initiation of PHB secretion occurs between 24 and $48 \mathrm{~h}$ after induction of PHB synthesis. Of the total PHB produced by the secreting strain, 36\% was collected in the secreted fraction and $64 \%$ remained in the internal fraction after $48 \mathrm{~h}$.

Secretion of PHB should help in downstream processing whereby PHB is separated from the cell mass, which can aid in PHB recovery and purification. Future studies will include a detailed comparison of secreted versus non-secreted PHB characteristics.

\section{Methods}

\section{Strains and plasmids}

Genetic parts were constructed in accordance with the BioBrick and BioFusion technical standards $[44,45]$. The BioFusion standard was specifically used to create phasin and signal peptide parts because this genetic fusion system is compatible with the original BioBrick standard $[45,46]$.

Descriptions of strains and plasmids used to study PHB and phasin production and translocation are provided as Table 2. Completed BioBrick parts were transformed in BL21-Gold (DE3) competent E. coli (Agilent Technologies, Santa Clara, CA) for protein expression studies. PHB production and secretion studies were carried out in E. coli XL1 Blue (Agilent Technologies, Santa Clara, CA). Plasmid pLG575 includes the coding regions for proteins HlyB and HlyD $[47,48]$. Plasmids pSB1AK3, pSB1A3, and pSB3K3 are BioBrick standard vectors for assembly and expression of BioBrick genetic devices [49].

\section{BioBrick and plasmid construction}

All restriction enzymes and related reagents were purchased from Thermo Fisher Scientific Inc. (Glen Burnie, MD). The signal peptide HlyA was made through synthetic design and construction as mention in Linton et al. 2012 (DNA 2.0, Menlo Park, CA) [35]. A BioFusioncompatible phasin BioBrick was constructed by isolating phaP1 from the genomic DNA of $R$. eutropha using PCR with primers PhaP1FOR and PhaP1REV that included the BioFusion prefix and suffix as overhanging ends (Table 2). The $620 \mathrm{bp}$ PCR product was isolated by gel electrophoresis, digested with EcoRI and SpeI, and ligated into pSB3K3. A PstI site was removed from phaP1 (while conserving amino acid sequence) using a QuikChange II Site-Directed Mutagenesis Kit and the QuikChange ${ }^{\circ}$ Primer Design Program (Agilent Technologies, Santa Clara, $\mathrm{CA}$ ). The designed primers (g114t and g114t_antisense) for site-directed mutagenesis are shown in Table 2. The

Table 2 Strains, plasmids, and oligonucleotides used in this study

\begin{tabular}{|c|c|c|}
\hline Strains & Relevant characteristics & Reference \\
\hline \multicolumn{3}{|l|}{ Strains } \\
\hline BL21-Gold (DE3) & E. coli B F $F^{-}$ompT hsdS $\left(\mathrm{rB}^{-} \mathrm{mB}^{-}\right) \mathrm{dcm}^{+} \mathrm{Tet}^{\mathrm{R}}$ gal $\lambda(\mathrm{DE} 3)$ endA Hte & Agilent technologies \\
\hline XL1 Blue & 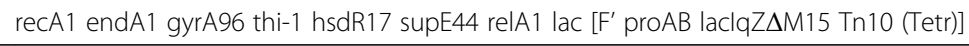 & Agilent technologies \\
\hline Cupriavidus necator $\mathrm{H} 16$ & Wild type, PHA producing & ATCC 17699 \\
\hline \multicolumn{3}{|l|}{ Plasmids } \\
\hline pLG575 & pACYC184 derivative, HlyBD, p15A origin, $\mathrm{Cm}^{\mathrm{R}}$ & [47] \\
\hline pBHR68 & pBluescript SK-, phbCAB genes from R. eutropha & [16] \\
\hline pSB1AK3 & High copy BioBrick vector, pMB1 origin, $A m p^{R}$ and $\operatorname{Kan}^{R}$ & [49] \\
\hline pSB1A3 & High copy BioBrick vector, pMB1 origin, Amp ${ }^{R}$ & [49] \\
\hline pSB3K3 & Medium copy BioBrick standard vector, p15A origin, $\operatorname{Kan}^{R}$ & [49] \\
\hline PCMEL1 & $\begin{array}{l}\text { phaP1, C-terminal BioFusion with HlyA signal peptide, Lac promoter (BBa_R0010), } \\
\text { RBS(BBa_B0034), in pSB1A3 }\end{array}$ & This study \\
\hline pCMEL2 & $\begin{array}{l}\text { phaP1, C-terminal BioFusion with HlyA signal peptide, Lac promoter (BBa_R0010), } \\
\text { RBS(BBa_B0034), in pSB3K3 }\end{array}$ & This study \\
\hline pCMEL3 & $\begin{array}{l}\text { phaP1, C-terminal BioFusion with HlyA signal peptide, Lac promoter (BBa_R0010), } \\
\text { RBS(BBa_B0034), in pBHR68 }\end{array}$ & This study \\
\hline \multicolumn{3}{|l|}{ Oligonucleotides } \\
\hline PhaP1FOR & 5'-gaattcgcggccgcttctagaatgatcctcaccccggaaca-3' & This study \\
\hline PhaP1REV & 5'- ctgcagcggccgctactagttcaggcagccgtcgtcttct-3' & This study \\
\hline $\mathrm{g} 114 \mathrm{t}$ & 5'-cgtcgagctgaaccttcaggtcgtcaagact-3' & This study \\
\hline g114t_antisense & 5'-agtcttgacgacctgaaggttcagctcgacg-3' & This study \\
\hline
\end{tabular}


PstI mutation in phaP1 was successfully carried out and confirmed by sequence analysis.

Step-wise assembly of composite BioBrick devices was primarily carried out in pSB1AK3. Completed devices were subsequently ligated into pSB1A3 and pSB3K3. The lac promoter (BBa_R0010) and ribosome binding site (BBa_B0034) were used as described in Linton et al. 2012 [35]. The pCMEL1 plasmid was used for studies on phasin translocation because its origin of replication (pMB1) was compatible with the origin of replication of pLG575 (p15A). BL21-Gold (DE3) was co-transformed with pCMEL1 and pLG575. The pCMEL3 plasmid was used for studies on type I secretion of PHA. The composite part containing the promoter, RBS, coding region, and terminator were cloned into PBHR68 from PCMEL2 by digestion with EcoRI and XhoI. XL1-Blue was co-transformed with pCMEL3 and pLG575 for PHA secretion studies. A schematic of the secretion system is presented in Figure 4.

\section{Cellular fractionation and western blotting}

Overnight cultures of E. coli BL21-Gold (DE3) harboring pCMEL1 and pLG575 were used to inoculate $(1: 100 \mathrm{v} / \mathrm{v}$ dilution) $100 \mathrm{ml}$ of LB media containing $25 \mu \mathrm{g} / \mathrm{ml}$ chloramphenicol (Acros Organics, Fair Lawn, NJ) and $50 \mu \mathrm{g} / \mathrm{ml}$ ampicillin (IBI Scientific, Peosta, IA) [50]. The lysozyme/ EDTA/osmotic shock and chloroform-based cellular fractionation procedures and methods for analyzing supernatant fractions are previously discussed in Linton et al. 2012 [35]. Briefly, $50 \mathrm{~mL}$ of cell culture were centrifuged and the pellet was resuspended in a buffer and subjected to osmotic shock. Centrifugation was used to

A

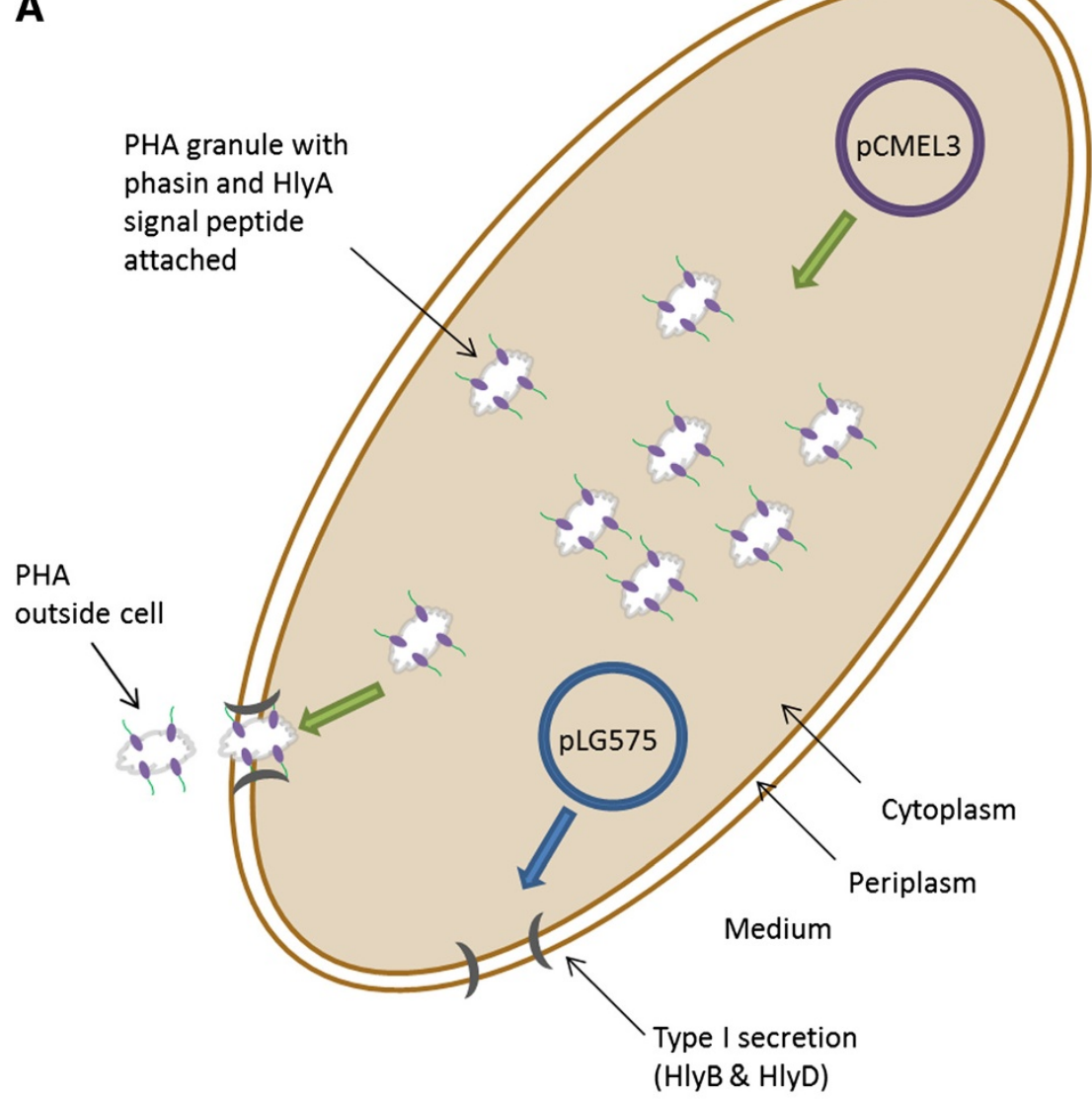

B

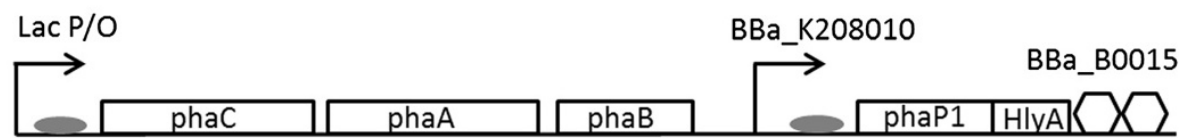

Figure 4 PHB secretion. A. Schematic for PHB secretion containing dual plasmid system pCMEL3 and pLG575. Phasin with attached signal peptide binds to PHB granule surface and the PHB-phasin-signal peptide complex is targeted for type I secretion. B. pCMEL3 plasmid consisting of phaC, phaC, and phaB genes from pBHR68. pCMEL3 also contains the genes needed for phasin-HylA production. 
separate the periplasm from spheroplast. Cytoplasm and membranes were fractionated via ultracentrifugation.

Approximately $40 \mu \mathrm{g}$ of protein from each of the respective fractioned samples were separated using precast $12 \%$ SDS-polyacrylamide tris-glycine gels (Jule Inc., Milford, CT). Electrophoresis operating conditions were used as specified by the manufacturer. Phasin immunoblotting was carried out using a PhaP1 specific antibody [51,52]. An Anti-Rabbit IgG HRP conjugated secondary antibody was purchased from Promega (Madison, WI). Respective primary and secondary antibody concentrations of 1:50,000 v/v and 1:2,500 v/v were used.

\section{PHB secretion studies}

All secretion studies were carried out in triplicate. Secretion studies were conducted with the secreting system (pCMEL3 + pLG575 in XL1 Blue) and non-secreting system (pBHR68 + pLG575 in XL1 Blue). The nonsecreting system does not contain phasin-HlyA.

\section{Media formulation and growth conditions}

$R$. eutropha was cultured following the methods outlined in Linton et al. 2012 [53]. M9 salts (Becton, Dickinson and Co, Sparks, MD) supplemented with 1.5\% (w/v) glucose (ACS grade, Acros Organics, Fair Lawn, NJ) and $0.2 \%(\mathrm{w} / \mathrm{v})$ yeast extract (Becton, Dickinson and Co, Sparks, MD) was used for PHB secretion studies in $E$. coli [38]. Overnight E. coli cultures harboring specific plasmids were inoculated from freezer stocks into $5 \mathrm{ml}$ of M9 media with chloramphenicol $(34 \mu \mathrm{g} / \mathrm{ml})$, ampicillin $(50 \mu \mathrm{g} / \mathrm{ml})$, and grown in an orbital shaker table at $220 \mathrm{rpm}$ at $37^{\circ} \mathrm{C}$. Overnight cultures were then used to seed larger $250 \mathrm{ml}$ flasks (50 ml media volume) at an initial optical density $\left(\mathrm{OD}_{600}\right)$ of 0.05 at time $0 \mathrm{~h}$. $0.1 \mathrm{mM}$ Isopropyl $\beta$-D-1-thiogalactopyranoside (IPTG) (Gold Biotechnology, Inc. St. Louis, MO) was added to each flask at time $0 \mathrm{~h}$. Flasks were removed at 24, and $48 \mathrm{~h}$ and analyzed for PHB. CFU/mL was measured at time points $0,4,6,8,12$, and $24 \mathrm{~h}$.

\section{Recovery of secreted PHB}

PHB granules can agglomerate together naturally and previous studies have demonstrated the use of Calcium chloride $\left(\mathrm{CaCl}_{2}\right)$ to enhance this process. A study by Fidler et al. used $\mathrm{CaCl}_{2}$ to purify PHB from lysed cells by selectively aggregating $\mathrm{PHB}$ granules. It was observed that PHB granules fell to the bottom of the test tube after addition of $\mathrm{CaCl}_{2}$ [54]. Another $\mathrm{CaCl}_{2}$ method for PHB recovery by Resch et al. used a low speed centrifugation step to further enhance PHB recovery from cell debris [55].

In this study, techniques for secreted PHB recovery were adapted from the methods outlined in [55]. At 24, and $48 \mathrm{~h} 0.01 \mathrm{M} \mathrm{CaCl}_{2}$ (final concentration, Avantor Performance Materials, Inc. Center Valley, PA) was added to the bacterial culture and mixed by inverting the tube several times. The tubes were then allowed to sit for 10 mins at room temperature and then centrifuged at $54 \times \mathrm{g}$ for $5 \mathrm{~min}$. The supernatant was removed and transferred to a fresh tube and the pellet was freeze dried. The supernatant was centrifuged at $3452 \times \mathrm{g}$ for $10 \mathrm{mins}$ and the pellet was freeze dried. The pellet from the first centrifugation contained secreted PHB with $\mathrm{CaCl}_{2}$ and the pellet from the second centrifugation contained bacterial mass and non-secreted PHB. Secretion studies and PHB analysis were conducted in triplicate.

\section{PHB concentration determination}

PHB concentrations were determined based on a NMRGC method described in Linton et al. 2012 [53]. Briefly, samples were lyophilized after which approximately $15 \mathrm{mg}$ of sample was mixed with equal volumes of sodium hypochlorite and deuterated chloroform. Samples were centrifuged and $1 \mathrm{H}$ NMR was carried out on the PHB fraction. PHB concentration was determined from a NMR-GC standard.

\section{Scanning electron microscopy (SEM)}

To visually show PHB secretion from E. coli, SEM was performed. SEM protocols were used as mentioned in [56]. Briefly, secreting and non-secreting strains were grown up overnight and fixed onto glass cover slips. Samples were mounted on aluminum stubs and sputter coated with $10 \mathrm{~nm}$ gold. SEM was carried out using a Hitachi S4000 SEM.

\section{Statistical analysis}

All growth $(\mathrm{CFU} / \mathrm{mL})$ and $\mathrm{PHB}$ yield studies were carried out in triplicate to show consistency of data. Statistical analysis was conducted with Statistical Analysis Software (SAS 9.3, SAS Institute Inc., Cary, NC). A two-way analysis of variance (ANOVA) with tukey post hoc comparison performed on significant results (confidence level 95\%).

\section{Competing interests}

The authors declare that they have no competing interests.

\section{Authors' contributions}

$A R$ and $E L$ conducted experiments and wrote the manuscript draft. CDM conceived and designed the experiments and wrote the manuscript. $\mathrm{AH}$ assisted with experiments and data analysis. RCS assisted with experimental design and manuscript revision. All authors read and approved the final manuscript.

\section{Acknowledgements}

The authors would also like to acknowledge FenAnn Shen and T.C. Shen in the Physics Department at Utah State University for assisting with the SEM. Marie K. Walsh in Nutrition, Dietetics and Food Sciences at Utah State University helped with phasin translocation studies. The authors would like to thank I. Barry Holland and Thorsten Jumpertz for the pLG575 plasmid. The authors would also like to acknowledge the gift of the primary phasin antibody from Anthony J. Sinskey and JoAnne Stubbe. This research was supported by the Utah State University Synthetic Bio-Manufacturing Center (SBC) and Utah Science Technology and Research initiative (USTAR). 
Received: 28 June 2013 Accepted: 12 September 2013

Published: 18 October 2013

\section{References}

1. Philp JC, Ritchie RJ, Guy K: Biobased plastics in a bioeconomy. Trends Biotechnol 2013, 31:65-67.

2. Keshavarz T, Roy I: Polyhydroxyalkanoates: bioplastics with a green agenda. Curr Opin Microbiol 2010, 13:321-326.

3. Dias JML, Lemos PC, Serafim LS, Oliveira C, Eiroa M, Albuquerque MGE, Ramos AM, Oliveira R, Reis MAM: Recent advances in polyhydroxyalkanoate production by mixed aerobic cultures: from the substrate to the final product. Macromol Biosci 2006, 6:885-906.

4. Madison LL, Huisman GW: Metabolic engineering of poly(3hydroxyalkanoates): from DNA to plastic. Microbiol Mol Biol Rev 1999 63:21-53.

5. Shang L, Fei Q, Zhang YH, Wang XZ, Fan DD, Chang HN: Thermal properties and biodegradability studies of poly(3-hydroxybutyrate-co-3hydroxyvalerate). Journal of Polymers and the Environment 2012, 20:23-28.

6. Mergaert J, Anderson C, Wouters A, Swings J: Microbial degradation of poly(3-hydroxybutyrate) and poly(3-hydroxybutyrate-co-3hydroxyvalerate) in compost. Journal of Environmental Polymer Degradation 1994, 2:177-183.

7. Jendrossek D, Handrick R: Microbial degradation of polyhydroxyalkanoates. Annu Rev Microbiol 2002, 56:403-432.

8. Jendrossek D, Schirmer A, Schlegel HG: Biodegradation of polyhydroxyalkanoic acids. Appl Microbiol Biotechnol 1996, 46:451-463.

9. Agnew DE, Pfleger BF: Synthetic biology strategies for synthesizing polyhydroxyalkanoates from unrelated carbon sources. Chemical Engineering Science 2012. In press. Available online, ISSN 0009-2509, http://dx.doi.org/10.1016/j.ces.2012.12.023.

10. Rehm BHA: Bacterial polymers: biosynthesis, modifications and applications. Nat Rev Microbiol 2010, 8:578-592.

11. Chanprateep S: Current trends in biodegradable polyhydroxyalkanoates. J Biosci Bioeng 2010, 110:621-632.

12. Akaraonye $\mathrm{E}$, Keshavarz T, Roy I: Production of polyhydroxyalkanoates: the future green materials of choice. J Chem Technol Biotechnol 2010, 85:732-743.

13. Gumel AM, Annuar MSM, Chisti Y: Recent advances in the production, recovery and applications of polyhydroxyalkanoates. J Polym and the Environ 2013, 21:580-605.

14. Numata K, Doi Y: Dual biosyntheses of poly[(R)-3-hydroxybutyric acid] and silk protein for the fabrication of biofunctional bioplastic. Polymer Journal 2011, 43:642-647

15. Xu C, Qiu Z: Crystallization behavior and thermal property of biodegradable poly(3-hydroxybutyrate)/multi-walled carbon nanotubes nanocomposite. Polymers for Advanced Technologies 2011, 22:538-544.

16. Spiekermann P, Rehm BHA, Kalscheuer R, Baumeister D, Steinbüchel A: A sensitive, viable-colony staining method using Nile red for direct screening of bacteria that accumulate polyhydroxyalkanoic acids and other lipid storage compounds. Arch Microbiol 1999, 171:73-80.

17. Grage K, Jahns AC, Parlane N, Palanisamy R, Rasiah IA, Atwood JA, Rehm BHA: Bacterial polyhydroxyalkanoate granules: biogenesis, structure, and potential use as nano-/micro-beads in biotechnological and biomedical applications. Biomacromolecules 2009, 10:660-669.

18. Rehm BHA: Polyester synthases: natural catalysts for plastics. Biochem J 2003, 376:15-33.

19. Pötter M, Müller $H$, Reinecke F, Wieczorek R, Fricke F, Bowien B, Friedrich B, Steinbüchel A: The complex structure of polyhydroxybutyrate (PHB) granules: four orthologous and paralogous phasins occur in ralstonia eutropha. Microbiology 2004, 150:2301-2311

20. Jacquel N, Lo C-W, Wei Y-H, Wu H-S, Wang SS: Isolation and purification of bacterial poly(3-hydroxyalkanoates). Biochem Eng J 2008, 39:15-27.

21. Pukatzki S, Ma AT, Revel AT, Sturtevant D, Mekalanos JJ: Type VI secretion system translocates a phage tail spike-like protein into target cells where it cross-links actin. Proc Natl Acad Sci USA 2007, 104:15508-15513.

22. Henderson IR, Navarro-Garcia F, Desvaux M, Fernandez RC, Ala'Aldeen D: Type $\mathrm{V}$ protein secretion pathway: the autotransporter story. Microbiol Mol Biol Rev 2004, 68:692-744.

23. Economou A, Christie PJ, Fernandez RC, Palmer T, Plano GV, Pugsley AP: Secretion by numbers: protein traffic in prokaryotes. Mol Microbiol 2006, 62:308-319.
24. Desvaux M, Hébraud M, Talon R, Henderson IR: Secretion and subcellular localizations of bacterial proteins: a semantic awareness issue. Trends Microbiol 2009, 17:139-145

25. York GM, Stubbe J, Sinskey AJ: New insight into the role of the PhaP phasin of Ralstonia eutropha in promoting synthesis of polyhydroxybutyrate. J Bacteriol 2001, 183:2394-2397.

26. Steinbuchel A, Aerts K, Babel W, Follner C, Kiebergesell M, Madkour MH, Mayer F, Pieper-Furst U, Pries A, Valentin HE, Wieczorek R: Considerations on the structure and biochemistry of bacterial polyhydroxyalkanoic acid inclusions. Can J Microbiol 1995, 41:94-105.

27. Giddings G, Allison G, Brooks D, Carter A: Transgenic plants as factories for biopharmaceuticals. Nat Biotechnol 2000, 18:1151-1155.

28. Maehara A, Ueda S, Nakano H, Yamane T: Analyses of a polyhydroxyalkanoic acid granule-associated 16-kilodalton protein and its putative regulator in the pha locus of Paracoccus denitrificans. J Bacteriol 1999, 181:2914-2921.

29. Wieczorek R, Pries A, Steinbuchel A, Mayer F: Analysis of a 24-kilodalton protein associated with the polyhydroxyalkanoic acid granules in Alcaligenes eutrophus. J Bacterio/ 1995, 177:2425-2435.

30. Mergulhão FJM, Summers DK, Monteiro GA: Recombinant protein secretion in escherichia coli. Biotechnol Adv 2005, 23:177-202.

31. Holland IB, Schmitt L, Young J: Type 1 protein secretion in bacteria, the ABC-transporter dependent pathway. Mol Membr Biol 2005, 22:29-39.

32. Hinsa SM, Espinosa-Urgel M, Ramos JL, O'Toole GA: Transition from reversible to irreversible attachment during biofilm formation by Pseudomonas fluorescens WCS365 requires an ABC transporter and a large secreted protein. Mol Microbiol 2003, 49:905-918.

33. Kenny B, Haigh R, Holland IB: Analysis of the haemolysin transport process through the secretion from Escherichia coli of PCM, CAT or $\beta$-galactosidase fused to the Hly C-terminal signal domain. Mol Microbiol 1991, 5:2557-2568.

34. Mackman N, Baker K, Gray L, Haigh R, Nicaud JM, Holland IB: Release of a chimeric protein into the medium from Escherichia coli using the C-terminal secretion signal of haemolysin. EMBO J 1987, 6:2835-2841.

35. Linton E, Walsh MK, Sims RC, Miller CD: Translocation of green fluorescent protein by comparative analysis with multiple signal peptides. Biotechnol J 2012, 7:667-676

36. Fernández LA, De Lorenzo V: Formation of disulphide bonds during secretion of proteins through the periplasmic-independent type I pathway. Mol Microbiol 2001, 40:332-346.

37. Lee SY, Yim KS, Chang HN, Chang YK: Construction of plasmids, estimation of plasmid stability, and use of stable plasmids for the production of poly(3-hydroxybutyric acid) by recombinant Escherichia coli. J Biotechnol 1994, 32:203-211.

38. Kang Z, Wang Q, Zhang HJ, Qi QS: Construction of a stress-induced system in Escherichia coli for efficient polyhydroxyalkanoates production. Appl Microbiol Biotechnol 2008, 79:203-208.

39. Choi Il, Lee SY: Efficient and economical recovery of poly(3hydroxybutyrate) from recombinant Escherichia coli by simple digestion with chemicals. Biotechnol Bioeng 1999, 62:546-553.

40. Ramachander TVN, Rohini D, Belhekar A, Rawal SK: Synthesis of PHB by recombinant $\mathrm{E}$. coli harboring an approximately $5 \mathrm{~kb}$ genomic DNA fragment from Streptomyces aureofaciens NRRL 2209. Int J Biol Macromol 2002, 31:63-69.

41. Molitoris HP, Moss ST, De Koning GJM, Jendrossek D: Scanning electron microscopy of polyhydroxyalkanoate degradation by bacteria. Appl Microbiol Biotechnol 1996, 46:570-579.

42. Peters $\mathrm{V}$, Rehm BHA: In vivo monitoring of PHA granule formation using GFP-labeled PHA synthases. FEMS Microbiol Lett 2005, 248:93-100.

43. Peters $V$, Becher $D$, Rehm BHA: The inherent property of polyhydroxyalkanoate synthase to form spherical PHA granules at the cell poles: The core region is required for polar localization. J Biotechnol 2007, 132:238-245

44. Idempotent vector design for standard assembly of biobricks. http://hdl.handle. net/1721.1/21168.

45. A New biobrick assembly strategy designed for facile protein engineering http://hdl.handle.net/1721.1/32535.

46. Anderson JC, Dueber JE, Leguia M, Wu GC, Arkin AP, Keasling JD: BglBricks: a flexible standard for biological part assembly. J Biol Eng 2010, 4:1. 
47. Mackman N, Nicaud JM, Gray L, Holland IB: Genetical and functional organisation of the Escherichia coli haemolysin determinant 2001. Molecular and General Genetics 1985, 201:282-288.

48. Jobling MG, Holmes RK: Construction of vectors with the p15a replicon, kanamycin resistance, inducible lacZa and pUC18 or pUC19 multiple cloning sites. Nucleic Acids Res 1990, 18:5315-5316.

49. Registry of standard biological parts. http://partsregistry.org/.

50. Sambrook J, Russel DW: Molecular cloning: a laboratory manual. Cold Spring Harbor, NY: Cold Spring Harbor Laboratory Press; 2001.

51. York GM, Junker BH, Stubbe J, Sinskey AJ: Accumulation of the PhaP phasin of Ralstonia eutropha is dependent on production of polyhydroxybutyrate in cells. J Bacteriol 2001, 183:4217-4226.

52. Tian J, He A, Lawrence AG, Liu P, Watson N, Sinskey AJ, Stubbe J: Analysis of transient polyhydroxybutyrate production in Wautersia eutropha $\mathrm{H} 16$ by quantitative Western analysis and transmission electron microscopy. J Bacteriol 2005, 187:3825-3832.

53. Linton E, Rahman A, Viamajala S, Sims RC, Miller CD: Polyhydroxyalkanoate quantification in organic wastes and pure cultures using a single-step extraction and 1H NMR analysis. Water Sci Technol 2012, 66:1000-1006.

54. Fidler S, Dennis D: Polyhydroxyalkanoate production in recombinant Escherichia coli. FEMS Microbiol Rev 1992, 103:231-235.

55. Resch S, Gruber K, Wanner G, Slater S, Dennis D, Lubitz W: Aqueous release and purification of poly([beta]-hydroxybutyrate) from Escherichia coli. J Biotechnol 1998, 65:173-182.

56. Mortensen T, Shen S, Shen F, Walsh MK, Sims RC, Miller CD: Investigating the effectiveness of St John's wort herb as an antimicrobial agent against mycobacteria. Phytother Res 2012, 26:1327-1333.

doi:10.1186/1754-1611-7-24

Cite this article as: Rahman et al: Secretion of polyhydroxybutyrate in Escherichia coli using a synthetic biological engineering approach. Journal of Biological Engineering 2013 7:24.

\section{Submit your next manuscript to BioMed Central and take full advantage of:}

- Convenient online submission

- Thorough peer review

- No space constraints or color figure charges

- Immediate publication on acceptance

- Inclusion in PubMed, CAS, Scopus and Google Scholar

- Research which is freely available for redistribution 